\title{
Effects on Mechanical Properties of Recycled PET in Cement-Based Composites
}

\author{
Liliana Ávila Córdoba, ${ }^{1}$ Gonzalo Martínez-Barrera, ${ }^{2}$ Carlos Barrera Díaz, \\ Fernando Ureña Nuñez, ${ }^{4}$ and Alejandro Loza Yañez ${ }^{5}$ \\ ${ }^{1}$ Facultad de Química, Universidad Autónoma del Estado de México, Paseo Colon Esquina Paseo Tollocan S/N, \\ 50180 Toluca, MEX, Mexico \\ ${ }^{2}$ Laboratorio de Investigación y Desarrollo de Materiales Avanzados (LIDMA), Facultad de Química, \\ Universidad Autónoma del Estado de México, Km. 12 de la Carretera Toluca-Atlacomulco, 50200 San Cayetano, MEX, Mexico \\ ${ }^{3}$ Centro Conjunto de Investigación en Química Sustentable UAEM-UNAM, Universidad Autónoma del Estado de México Campus \\ El Rosedal, Autopista Ixtlahuaca-Atlacomulco, Km 14.5, 50200 San Cayetano, MEX, Mexico \\ ${ }^{4}$ Instituto Nacional de Investigaciones Nucleares, Carretera México-Toluca S/N, 52750 La Marquesa Ocoyoacac, MEX, Mexico \\ ${ }^{5}$ Facultad de Ingeniería, Universidad Autónoma del Estado de México, Avenida Universidad S/N, Cerro de Coatepec, \\ Ciudad Universitaria, 50110 Toluca, MEX, Mexico
}

Correspondence should be addressed to Gonzalo Martínez-Barrera; gonzomartinez02@yahoo.com.mx

Received 29 March 2013; Accepted 22 May 2013

Academic Editor: Osman Gencel

Copyright (C) 2013 Liliana Ávila Córdoba et al. This is an open access article distributed under the Creative Commons Attribution License, which permits unrestricted use, distribution, and reproduction in any medium, provided the original work is properly cited.

Concretes consisting of portland cement (OPC), silica sand, gravel, water, and recycled PET particles were developed. Specimens without PET particles were prepared for comparison. Curing times, PET particle sizes, and aggregate concentrations were varied. The compressive strength, compressive strain at yield point, and Young modulus were determined. Morphological and chemical compositions of recycled PET particles were seen in a scanning electron microscopy. Results show that smaller PET particle sizes in lower concentrations generate improvements on compressive strength and strain, and Young's modulus decreases when the size of PET particles used was increased.

\section{Introduction}

Polyethylene terephthalate (PET) is one of the most used materials in the packaging of several kinds of products. The packages made with PET are light, transparent, and with high resistance to impact, they do not interact chemically with the contents, and they are not toxic. All these characteristics have made them gain presence in the polymer market and earn a major presence in the global industry. The growth demand in Mexico has been estimated 13\% annually since 2000 [1]. Mexico has become the first per capita market of water packaged in PET bottles around the world. The annual average consumption per person is 234 liters; it means $13 \%$ of water sold in the whole world via PET bottles takes place in Mexico.
During 2009, the massive PET disposal in Mexico has reached more than 7800 million of nonreturnable bottles, because the nonbiodegradability nature of this material and the solid handle materials in all state jurisdictions have experienced an important impact. Approximately, 21.3 million bottles will be used every day by consumers; it is estimated that only $20 \%$ of these bottles will eventually reach the facilities for recycling solid, and the rest will be accumulated in rubbish dumps [2].

PET recycling consists in the transformation of bottles through two different kinds of processes: (1) mechanical process is the most employed physical process to recycle PET. It has three stages that include separation, washing, and grinding of containers. With this process, PET flakes produced can be directly employed without the need of being reprocessed as 
pellets in the creation of products by injection or extrusion; (2) chemical process consists of the separation of the basic components or monomers. The methanolysis, glycolysis, and hydrolysis are the elemental processes to achieve this transformation.

One transcendental alternative to recycling PET materials consists of using them as substitute of concrete aggregates. Due to demands of technological development in the construction area, the possibility for generating alternative materials that can be applied with increasing functionality, low costs, and better physical, chemical, and mechanical properties than conventional materials is being explored [3-5].

Fiber-reinforced concrete represents the current tendency to apply more efficient crack-resistant concrete. For instance, PET has been widely used to produce fibers, particles, or flakes to obtain cement-based products with improved properties $[6,7]$. Several studies using reinforced concrete with polymer fibers like polypropylene, polystyrene, polyethylene terephthalate, and polyethylene have evidenced variation of concrete properties according to the nature and size of the aggregate $[8,9]$.

Referring to environmental aspects, Rebeiz concludes that the inclusion of recycled PET can help diminish the production costs of concrete allowing long term disposal of plastics [10].

The effects of light aggregates of recycled PET in reinforced concrete were analyzed by compression, tension resistance, elasticity module, and density. Choi et al. concluded that 28-day compression index using a PET concentration of $75 \%$ diminishes approximately by $33 \%$ compared to plain concrete; however workability improves by $123 \%$ [11].

Another research showed that replacement of sand with less than $50 \%$ by volume with $5 \mathrm{~mm}$ granulated PET affects neither compression nor flexion strength [12]. Ochi et al. describe a method that can be used to produce concretereinforcing PET fiber from used PET bottles. By using this method, concrete and PET fibers are easily mixed with fiber contents as high as 3\% [13].

Fibers with lengths of 10,15 , and $20 \mathrm{~mm}$ and volume fractions of $0.05,0.18$, and $0.30 \%$ related to the volume of the concrete were used. Physical and mechanical characterizations of concrete were performed, including determination of compressive strength, flexural strength, Young's modulus, and fracture toughness, as well as pore analysis using mercury intrusion and scanning electron microscopy. Flexure and impact tests were performed after 28 and 150 days. No significant effects on compressive strength and modulus of elasticity were observed with the addition of fibers [6]. Moreover, Young's modulus decreased as fiber volume increased. At 28 days, concrete flexural toughness and impact resistance increased with the presence of PET fibers, except for the sample with $0.05 \%$ by volume [6].

Other authors have made preliminary analysis of concrete reinforced and waste polyethylene terephthalate as an aggregate [14-16].

In the present paper, compressive strength and Young's modulus of cement-based materials with recycled PET were evaluated. Particle sizes and concentrations of recycled PET were obtained from waste bottles.
TABLE 1: Sieve analysis of silica sand (Fineness modulus $=1.59$ ).

\begin{tabular}{lccc}
\hline $\begin{array}{l}\text { Sieve size } \\
\text { (number) }\end{array}$ & Retained (g) & $\begin{array}{c}\text { \% Retained } \\
\text { (individual) }\end{array}$ & $\begin{array}{c}\text { \% Retained } \\
\text { (cumulative) }\end{array}$ \\
\hline 16 & 0 & 0 & 0 \\
30 & 79.0 & 29 & 29 \\
50 & 74.9 & 27 & 56 \\
100 & 52.4 & 19 & 75 \\
200 & 36.9 & 13 & 88 \\
Bottom tray & 33.7 & 12 & 100 \\
\hline
\end{tabular}

TABLE 2: Sieve analysis of gravel.

\begin{tabular}{lccc}
\hline Sieve size (in) & Retained (g) & $\begin{array}{c}\text { \% Retained } \\
\text { (individual) }\end{array}$ & $\begin{array}{c}\text { \% Retained } \\
\text { (cumulative) }\end{array}$ \\
\hline $3 / 4$ & 0 & 0 & 0 \\
$3 / 8$ & 20.3 & 2 & 2 \\
4 & 902.8 & 91 & 93 \\
8 & 57.8 & 6 & 99 \\
Bottom tray & 7 & 1 & 100 \\
\hline
\end{tabular}

\section{Materials and Methods}

2.1. Specimen Preparation. Before preparing concrete specimens, one set of PET flakes was obtained from recycled PET bottles, in three different sizes: $0.5,1.5$, and $3 \mathrm{~mm}$, and was used in concentrations of $1.0,2.5$, and $5.0 \%$ by volume; these values were intentionally selected higher than those reported in previous investigations in order to avoid problems concerning homogeneity and workability, even with the use of plasticizer additives [17].

To obtain PET flakes for being added to concrete, in first stage, PET bottles were collected and cut. In order to achieve homogeneous size and make the cutting easy, only the body was used, excluding the neck and the bottom of them. First cut provided $50 \mathrm{~mm}$ long and $5 \mathrm{~mm}$ width (in average) PET flakes, and with a second cut, one-fifth of the original size was obtained. Finally, these flakes were submitted to a grinding process for one hour, in an SG Granulator model SG-2324E, and screened for 45 minutes through different sieves (nos. $6,10,14,18$, and 35 ), corresponding to $3.3,2.0,1.4,1.0$, and $0.5 \mathrm{~mm}$, respectively.

Different mixes were elaborated with portland cement (OPC); silica sand (1.4 mm size); gravel (9.5 mm maximum size), and water. Proportions of components in the mixes were $1 / 2.75$ for cement/aggregates, with water/cement ratio of 0.485 . All materials were mixed according to practice ASTM C-305 [18]. Sand and gravel aggregates were obtained from Calimaya county and Tula Hidalgo, Mexico, respectively.

Sieve analysis of silica sand and gravel aggregates is shown in Tables 1 and 2.

Three different sizes of PET flakes, 0.5, 1.5, and $3.0 \mathrm{~mm}$, were considered for the study, and for each size, three different concentrations of recycled PET particles were considered, $1.0,2.5$, and $5.0 \%$ by volume as shown in Table 3. 
TABLE 3: Components of concrete with recycled PET.

\begin{tabular}{lcccccc}
\hline PET $($ vol \%) & PET $(\mathrm{g})$ & Portland cement $(\mathrm{g})$ & Silica sand $(\mathrm{g})$ & Gravel $(\mathrm{g})$ & Water $(\mathrm{g})$ Total volume* $\left.^{*} \mathrm{~cm}^{3}\right)$ \\
\hline 1.0 & 3.26 & 420 & 914.7 & 1152 & 413 & 1338.9 \\
2.5 & 8.17 & 420 & 909.8 & 1152 & 413 & 1339.9 \\
5.0 & 16.33 & 420 & 901.6 & 1152 & 413 & 1342.8 \\
\hline
\end{tabular}

${ }^{*}$ Total volume was calculated considering specific gravity $\left(\mathrm{g} / \mathrm{cm}^{3}\right)$ of each material, as follows: PET (1.45), cement (3.15), silica sand (2.55), gravel (2.67), and water (1.00).

TABLE 4: Physical and mechanical properties of PET.

\begin{tabular}{lcc}
\hline Mechanical properties & Units & Value \\
\hline Density & $\mathrm{lbs} / \mathrm{in}^{3}$ & 0.0499 \\
Water absorption, $24 \mathrm{~h}$ & $\%$ & 0.10 \\
Specific gravity & $\mathrm{g} / \mathrm{cm}^{3}$ & 1.38 \\
Tensile strength at break, $73^{\circ} \mathrm{F}$ & $\mathrm{psi}$ & 11,500 \\
Tensile modulus, $73^{\circ} \mathrm{F}$ & $\mathrm{psi}$ & $4 \times 10^{5}$ \\
Elongation at break, $73^{\circ} \mathrm{F}$ & $\%$ & 70 \\
Flexural strength, $73^{\circ} \mathrm{F}$ & $\mathrm{psi}$ & 15,000 \\
Flexural modulus, $73^{\circ} \mathrm{F}$ & $\mathrm{psi}$ & $4 \times 10^{5}$ \\
\hline
\end{tabular}

2.2. Physical and Mechanical Properties of PET. For reference, some physical and mechanical properties of PET are presented in Table 4 .

After mixing, concrete cylindrical specimens $\left(2.0^{\prime \prime}\right.$ diameter and $4.0^{\prime \prime}$ long) were molded. After 24 hours, they were placed in a controlled temperature room (at $23.0 \pm 2.0^{\circ} \mathrm{C}$ and 95\% of relative humidity according to ASTM C/192 M-00) [19], with the surface exposed to moisture. The moist room conditions were the same as above, according to ASTM C-511 [20]. It is important to remark that PET flakes replaced silica sand.

2.3. Mechanical Tests. Compressive strength evaluation of all concrete cylindrical specimens was carried out in an universal testing machine model 70-S17C2 (Controls, Cernusco, Italy), according to ASTM C-39M-01 [21], located at Laboratory of Research and Development of Advanced Materials (LIDMA) of the Autonomous University of the State of Mexico (UAEM). Specimens were tested after 7 and 28 days of moist curing. Testing tolerance allowed for the specimens was 7 days \pm 6 hours and 28 days \pm 12 hours.

2.4. Morphological Characterization. Before mechanical testing, some PET flakes were dried in a rotovapor for 24 hours; then their surfaces, particle size distribution, and chemical composition were analyzed by a scanning electron microscopy (SEM) in a JEOL model JSM-5200 machine, in the secondary-electron mode.

\section{Results and Discussion}

The composition and morphological surface of recycled PET particles were evaluated by a scanning electron microscopy
TABLE 5: Compressive strength values of plain concrete.

\begin{tabular}{lc}
\hline Curing time (days) & Compressive strength $(\mathrm{MPa})$ \\
\hline 7 & 19.36 \\
28 & 26.76 \\
\hline
\end{tabular}

with EDS. The composition shows $72.55 \%$ of carbon and $27.45 \%$ of oxygen.

Recycled PET particles varying from $134 \mu \mathrm{m}$ to $1 \mathrm{~mm}$ were obtained following a first cutting process of PET bottles (Figure 1(a)). Applying a continuous cutting process, PET particle sizes diminish as seen in Figure 1(b), with sizes less than $100 \mu \mathrm{m}$. In the present work, we decided to use PET particles ranging from 0.5 to $3.0 \mathrm{~mm}$.

3.1. Compressive Strength. Compressive strength values of plain concrete are reported in Table 5.

Compressive strength values of concretes made with PET are shown in Figure 2. Analysis in terms of (a) PET particle size, (b) PET particle concentration, and (c) curing time was realized. Values of concrete strength range from 10.0 to $21.3 \mathrm{MPa}$, with a maximum improvement of $40 \%$ when $1.5 \mathrm{~mm}$ PET particles is added. Concretes without PET particles show moderate values, but when adding different sizes and volume percentages of PET particles, compressive strength increases. Moreover, the compressive strength values increase progressively for curing times ranging from 7 to 28 days given the condition that PET particle sizes do not exceed $1.5 \mathrm{~mm}$ as found in this investigation. Such behavior can be related to the presence of non degradable material (PET), which in principle can reduce the cement hydration. This is based on results, due to the fact that compressive strength at 7 days is less than the one obtained at 28 days.

According to PET particle size, the values are higher for concrete with $1.5 \mathrm{~mm}$ PET particles and lower for those with $3.0 \mathrm{~mm}$ PET particles. Moreover, the highest values are obtained for $2.5 \%$ by volume of PET particles. As it is known, the strength of materials can be improved by blending, insertion of fibers, using fillers, and/or combinations of these techniques. Smaller particles usually provide more reinforcement.

3.2. Compressive Strain at Yield Point. Results for compressive strain at the yield point are presented in Figure 3. The values for concretes with PET particles vary from 0.0032 to $0.009 \mathrm{~mm} / \mathrm{mm}$, higher than standard values for portland cement (OPC) concrete $(0.003 \mathrm{~mm} / \mathrm{mm})$. 


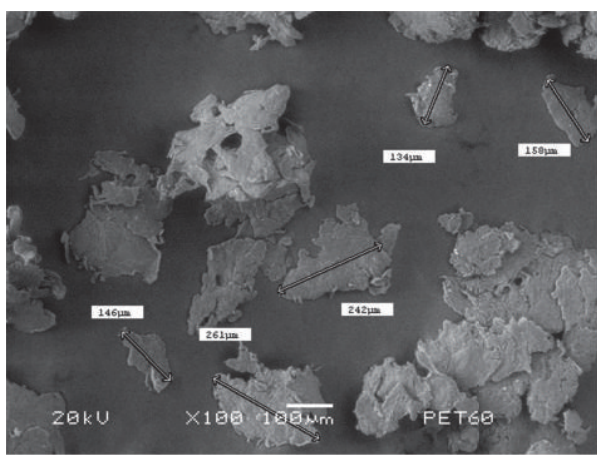

(a)

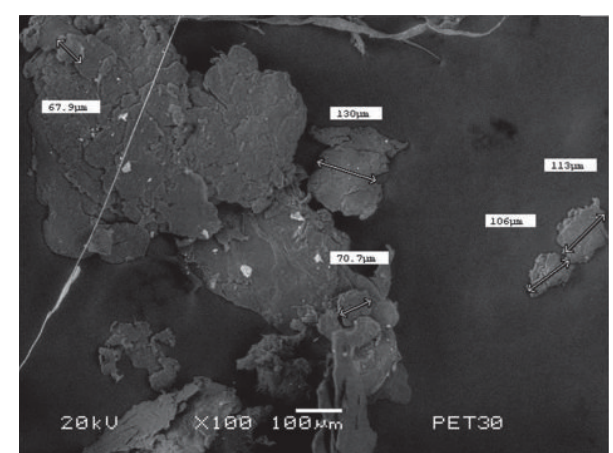

(b)

FIgUre 1: SEM images of (a) cut PET and (b) grinded PET.

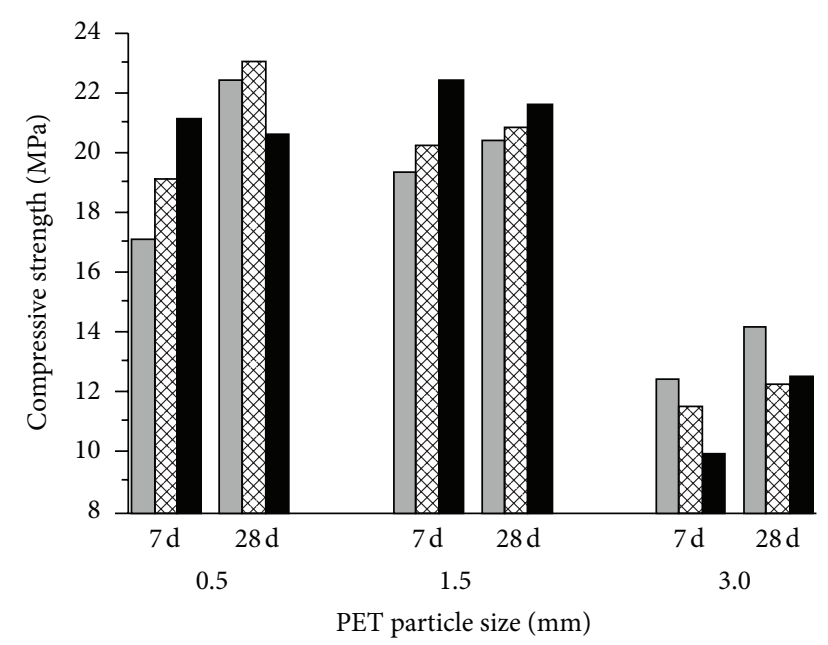

PET (vol\%)

$\square 1.0$

2.5

FIGURE 2: Compressive strength of concrete with recycled PET particles.

Different behaviours for concretes are seen. For concrete with PET particles of $0.5 \mathrm{~mm}$ and $1.5 \mathrm{~mm}$ of size, a continuous increase of compressive strain as a function of time can be observed. The highest compressive strain values are for concrete with $1.5 \mathrm{~mm}$ PET particles, followed by concrete with $0.5 \mathrm{~mm}$ PET particles. Nevertheless, bigger PET particle sizes $(3.0 \mathrm{~mm})$ generate lower compressive strain values.

In terms of time dependence, at 28 days of curing time, a minimum and maximum can be seen when using $0.5 \mathrm{~mm}$ or $1.5 \mathrm{~mm}$, respectively. The PET particle concentration constitutes a minority component but plays a role in enhancing the compressive strain values with respect to concrete made with $3.0 \mathrm{~mm}$ PET particle size. The values decrease for higher concentration of PET particles and higher sizes, comparing results of concrete tested with PET. Thus, higher sizes mean detrimental values for strain. This can be noticed in Figure 2 where compressive strength shows roughly $40 \%$ higher values

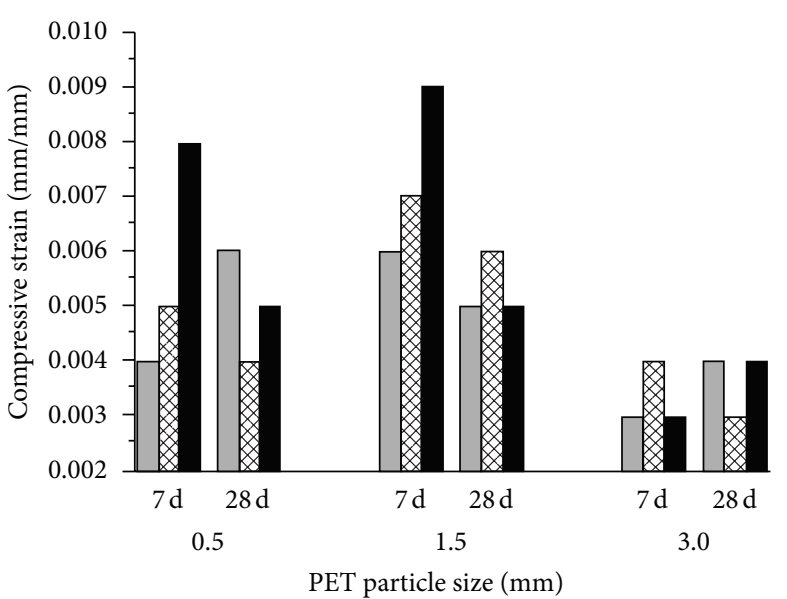

PET (vol\%)

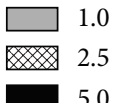

FIGURE 3: Compressive strain of concrete with recycled PET particles.

for 0.5 and $1.5 \mathrm{~mm}$ PET particle sizes than values obtained for $3.0 \mathrm{~mm}$ PET particle size. From Figure 2 and results shown in Table 5, it can be seen that compressive strength of plain concrete increased by $12 \%$ compared to concrete made with $1.5 \mathrm{~mm}$ PET particle size (which was the best result with PET), and the lowest strength was obtained in concrete made with $3 \mathrm{~mm}$ PET particle size (46\% compared to plain concrete).

3.3. Modulus of Elasticity under Compression. Figure 4 shows modulus of elasticity of concretes under compression; the values range from 1.1 to $5.2 \mathrm{GPa}$, which means a maximum improvement of $153 \%$ with respect to plain concrete when PET particles are added. The highest values are for concrete with $1.5 \mathrm{~mm}$ PET particles at a concentration of $2.5 \%$ by volume and 28 days of curing time. On the other hand, the lowest value was obtained with $3.0 \mathrm{~mm}$ PET particle size, at a concentration of $5.0 \%$ by volume and 28 days of curing 


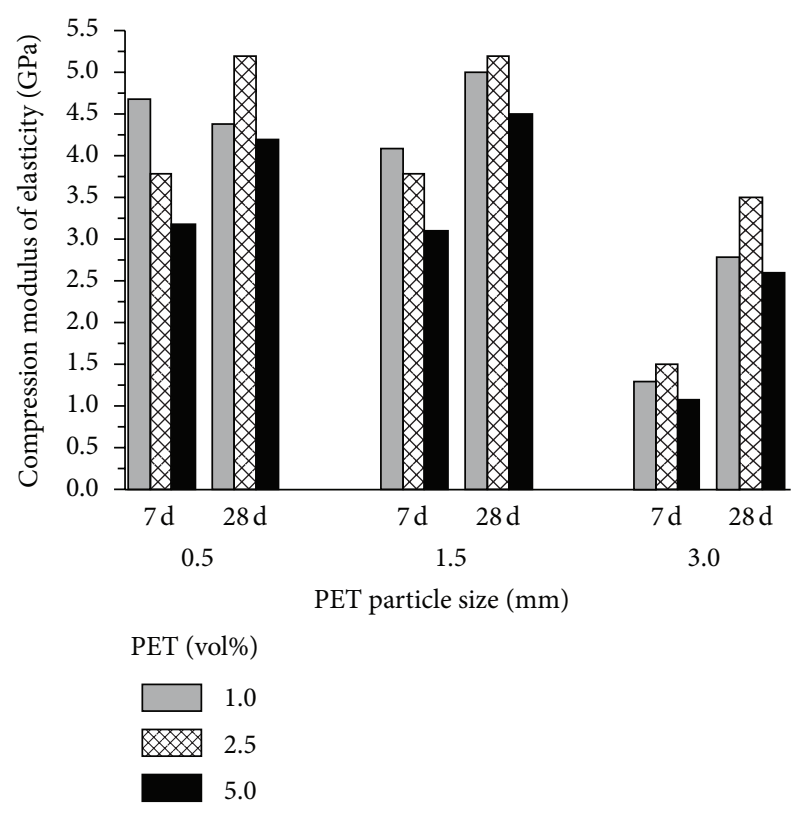

Figure 4: Modulus of elasticity under compression of concrete with recycled PET particles.

time. In general, the time dependence of concretes with PET particles shows maximum values at 28 days.

When analyzing elasticity results depending on PET particle size, the values are increasing from $0.5 \mathrm{~mm}$ to $1.5 \mathrm{~mm}$, but for $3.0 \mathrm{~mm}$ the values decrease.

Finally, the highest Young's modulus was obtained with $0.5 \mathrm{~mm}$ PET particles and $2.5 \%$ by volume of PET in the concrete mix. For $1.5 \mathrm{~mm}$ PET particles, Young's modulus is quite the same for every dose of PET used (1.0, 2.5, and 5.0\% by volume).

\section{Conclusions}

As expected, mechanical properties of the concrete depend on the PET particle size and its concentration. Lower sizes and concentrations of PET particle create less space in the concrete, and in consequence the compressive strength and the compression strain increase and Young's modulus decreases when the size of PET particles used was increased. Whenever less PET size is used in the concrete mix, deformations tend to be lower but maximum stresses are increased in magnitude.

The highest compressive strength was obtained for PET particle sizes of $0.5 \mathrm{~mm}$ and $2.5 \%$ volume and cured for 28 days, while the highest strain values were detected for $1.5 \mathrm{~mm}$ and $5.0 \%$ volume and cured for 7 days.

On the other hand, in absolute terms, the highest Young's modulus was obtained using $0.5 \mathrm{~mm}$ PET at a $2.5 \%$ dose in the concrete mix. We can also conclude that PET size has an inverse relationship to the Young's modulus obtained, which means as less PET size is used, Young's Modulus increases.

\section{Acknowledgments}

The authors thank the National Council of Science and Technology of México (CONACYT) for the scholarship support and for the achievement of this research and Environmental Sciences Graduate Program of Universidad Autónoma del Estado de México (UAEM). They thank also Eng. Carlos Uriel de la Rosa Serrano, Professor José Saturnino Pérez Fajardo (chief of Materials Laboratory of Faculty of Engineering of Universidad Autónoma del Estado de México), and Mr. Arcadio Estrada Nava for the technical support.

\section{References}

[1] J. Treviño, "Asociación para Promover el Reciclado del PET," A.C. APREPET. México, 2001, http://www.aprepet.org.mx/.

[2] "Beverage Marketing Corporation Report," Tech. Rep., The Global Bottled Water Market, 2010, http://www.beveragemarketing.com/.

[3] J. P. Schaffer, "Materiales compuestos," in Ciencia y Diseño de Ingeniería de Los Materiales, pp. 552-581, Compañía Editorial Continental, México city, México, 2000.

[4] K. Gurudatt, P. De, A. K. Rakshit, and M. K. Bardhan, "Dopedyed polyester fibers from recycled PET wastes for use in molded automotive carpets," Journal of Industrial Textiles, vol. 34, no. 3, pp. 167-179, 2005.

[5] W. F. Smith and J. Hashemi, Fundamentos de La Ciencia e Ingeniería de Materiales, McGraw Hill, New York, NY, USA, 2006.

[6] F. Pelisser, M. O. Klegues, P. J. Gleize, and R. H. Ramos, "Mechanical properties of recycled PET fibers in concrete," Materials Research, vol. 15, no. 4, pp. 1-8, 2012.

[7] J. T. San-José, I. Vegas, and A. Ferreira, "Reinforced polymer concrete: physical properties of the matrix and static/dynamic bond behaviour," Cement and Concrete Composites, vol. 27, no. 9-10, pp. 934-944, 2005.

[8] M. E. Tawfik and S. B. Eskander, "Polymer concrete from marble wastes and recycled poly(ethylene terephthalate)," Journal of Elastomers and Plastics, vol. 38, no. 1, pp. 65-79, 2006.

[9] B. Israngkura and Y. Ungkoon, "Bond performance of fiber reinforced polymer (FRP) bars in Autoclaved Aerated Concrete," Journal of Civil Engineering and Architecture, vol. 4, pp. 41-44, 2010.

[10] K. S. Rebeiz, “Time-temperature properties of polymer concrete using recycled PET," Cement and Concrete Composites, vol. 17, no. 2, pp. 119-124, 1995.

[11] Y.-W. Choi, D.-J. Moon, J.-S. Chung, and S.-K. Cho, "Effects of waste PET bottles aggregate on the properties of concrete," Cement and Concrete Research, vol. 35, no. 4, pp. 776-781, 2005.

[12] O. Y. Marzouk, R. M. Dheilly, and M. Queneudec, "Valorization of post-consumer waste plastic in cementitious concrete composites," Waste Management, vol. 27, no. 2, pp. 310-318, 2007.

[13] T. Ochi, S. Okubo, and K. Fukui, "Development of recycled PET fiber and its application as concrete-reinforcing fiber," Cement and Concrete Composites, vol. 29, no. 6, pp. 448-455, 2007.

[14] J. M. L. Reis and E. P. Carneiro, "Evaluation of PET waste aggregates in polymer mortars," Construction and Building Materials, vol. 27, no. 1, pp. 107-111, 2012.

[15] D. Foti, "Preliminary analysis of concrete reinforced with waste bottles PET fibers," Construction and Building Materials, vol. 25, no. 4, pp. 1906-1915, 2011. 
[16] N. Saikia and J. de Brito, "Waste polyethylene terephtalate as an aggregate in concrete," Materials Research, vol. 16, no. 2, pp. 341350, 2013.

[17] American Concrete Institute-ACI Committee, ACI 544. IR-96: State of the Art Report on Fiber Reinforced Concrete, chapter 4, ACI Committee, Detroit, Mich, USA, 1996.

[18] American Society for Testing Materials (ASTM), Standard Practice For Mechanical Mixing of Hydraulic Cement Pastes and Mortars of Plastic Consistency, 1999.

[19] American Society for Testing Materials (ASTM), Standard Practice For Making and Curing Concrete Test Specimens in the Laboratory, 2000.

[20] American Society for Testing Materials (ASTM), Standard Specification For Mixing Rooms, Moist Cabinets, Moist Rooms, and Water Storage Tanks Used in the Testing of Hydraulic Cements and Concrets, 1998.

[21] American Society for Testing Materials (ASTM), Standard Test Method For Compressive Strenght of Cylindrical Concrete Specimens, 2001. 

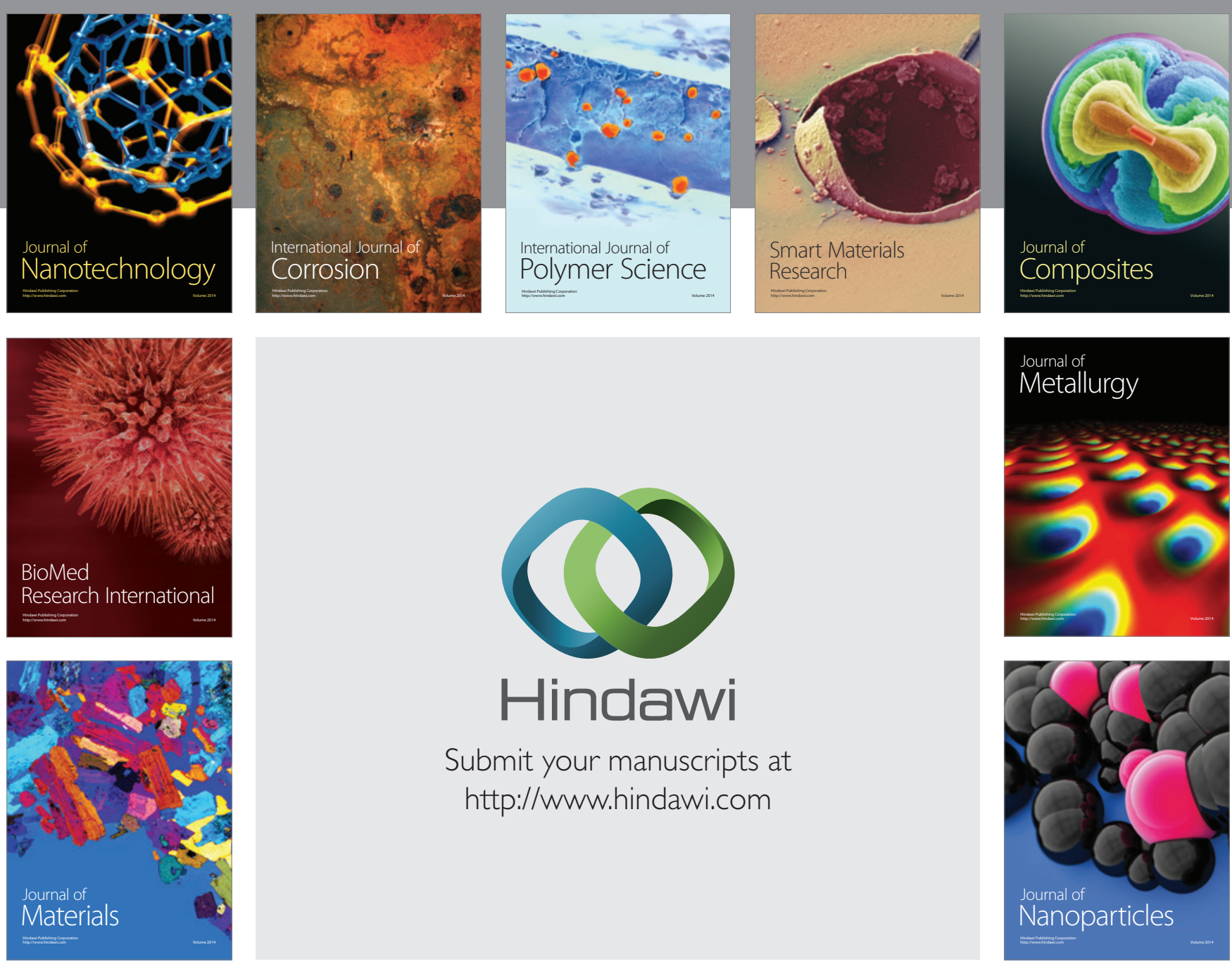

Submit your manuscripts at http://www.hindawi.com
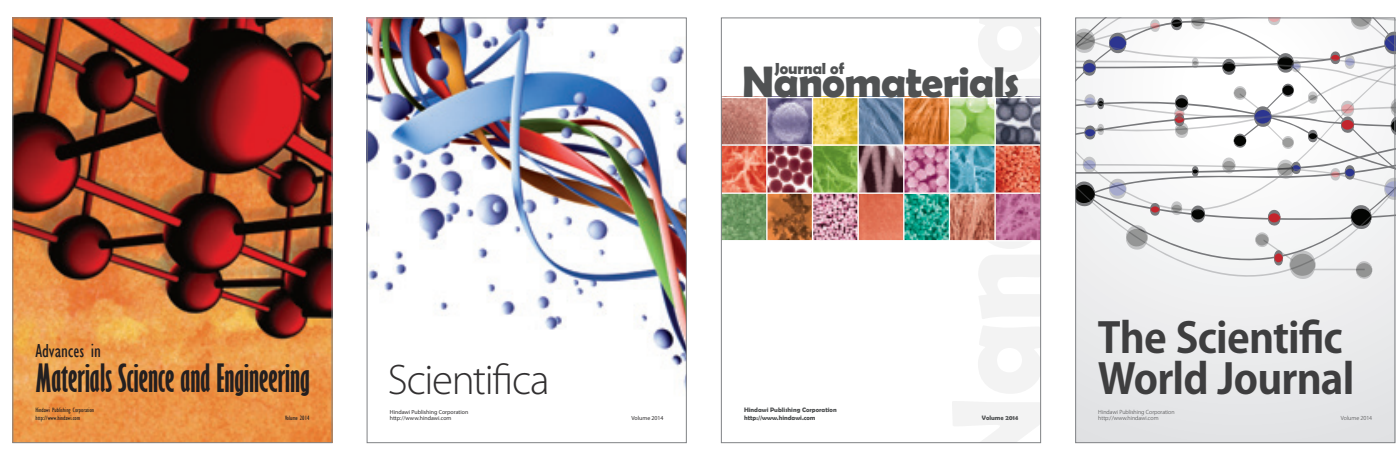

\section{The Scientific World Journal}
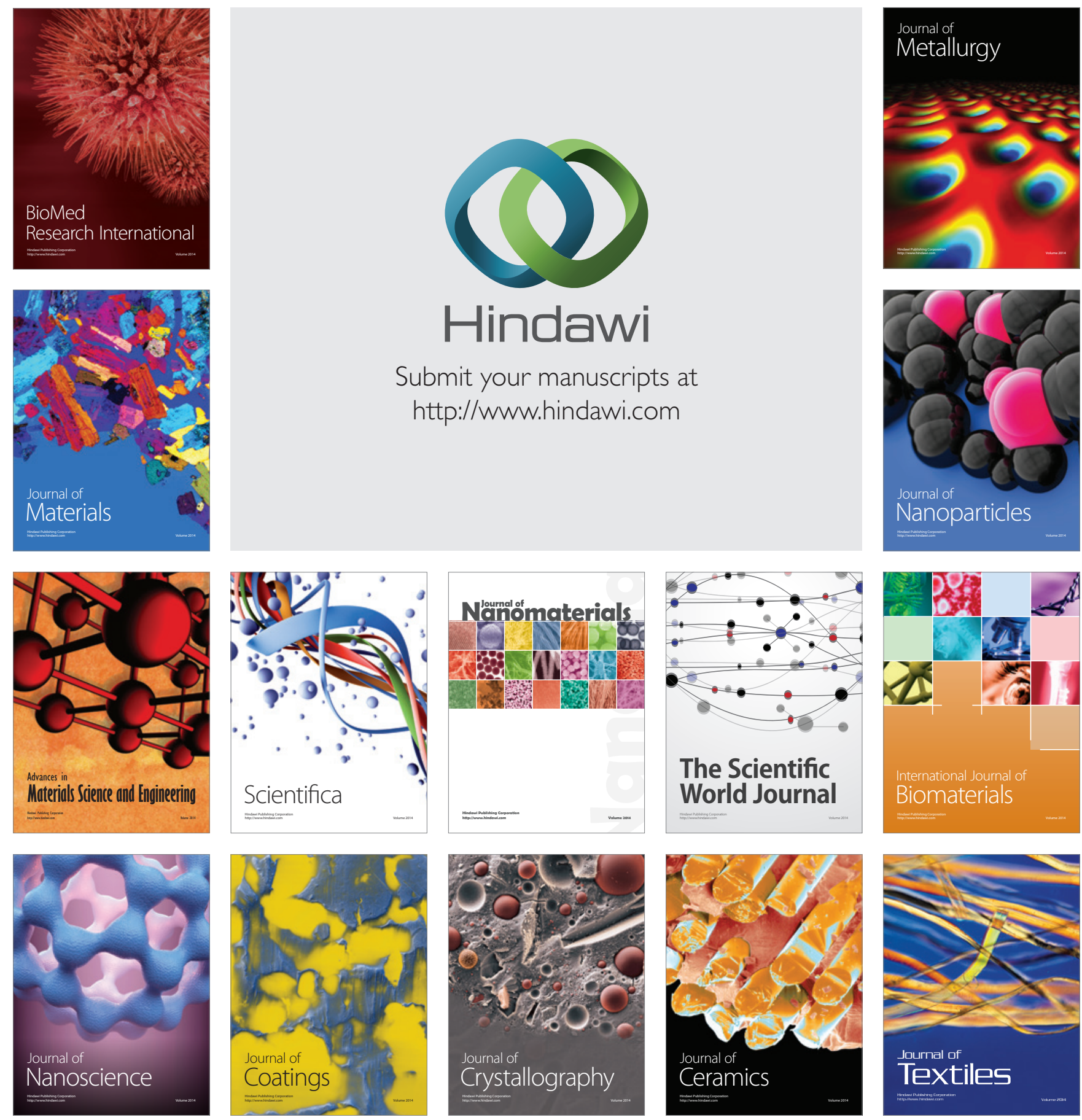